\title{
AGUDIZACIÓN ULTRA NEOLIBERAL, EDUCACIÓN Y FORMACIÓN DOCENTE EN BRASIL Y ARGENTINA
}

\author{
Solange Martins Oliveira Magalhães \\ Universidade Federal de Goiás (UFG), Goiânia, Goiás, Brasil \\ Sonia Araujo \\ Universidad Nacional del Centro de la Provincia de Buenos Aires \\ (UNCPBA), Tandil, Buenos Aires, Argentina \\ Susana Beatriz Argüello \\ Universidad Nacional de Jujuy (UNJu), San Salvador de Jujuy, Jujuy, Argentina
}

\begin{abstract}
RESUMEN: El artículo analiza el devenir de las políticas neoliberales en el campo de la educación en general y de la formación docente en particular en Brasil y Argentina desde la década de 1990. En primer lugar se plantea el neoliberalismo como movimiento ideológico que a partir de las décadas de 1970 y 1980 deriva en un período de re-estructuración económica, de reajustes sociales y políticos, y nuevas decisiones gubernamentales de acuerdo con las directrices neoliberales. Se señala el papel de los organismos internacionales como la UNESCO, el BM y el BID como actores que tuvieron un lugar fundamental en la difusión de estas ideas orientadas a minimizar el papel del Estado y fortalecer la iniciativa privada, contribuyendo directamente al sostenimiento de la desigualdad social. El texto recorre legislaciones, programas y proyectos formulados y desarrollados en Brasil y Argentina que si bien dan cuenta de diferencias nacionales importantes derivadas de factores exógenos y endógenos de los propios países, al mismo tiempo expresan el poder de la influencia regulatoria de los organismos internacionales en la formación de profesores.
\end{abstract}

Palabras Clave: Neoliberalismo. Políticas neoliberales. Formación de profesores.

\section{NOTA 1: AGUDIZACIÓN DEL NEOLIBERALISMO Y SUBORDINACIÓN SOCIAL}

Con la crisis de las condiciones de acumulación del capital y de la perpetuación del poder de las élites económicas (HARVEY, 2005; 2009), ocurrida durante las décadas de 1970 y 1980, se hizo cada vez más evidente la incapacidad del sistema capitalista, organizado sobre el modelo fordista, en controlar sus contradicciones inherentes, entrando en crisis cíclicas que colocaron a los países del llamado Primer Mundo en profunda recesión económica. 
La solución fue guiada por las ideas del austríaco Hayek, quien daba centralidad a un nuevo tipo de sistema que diferenciaba el Estado Liberal del Estado de Bienestar Social, con la declaración de la opción de desarrollo de una política de intervención mínima. La intervención política, aunque abogó un discurso de mayor libertad y autonomía, prescribía la adopción de prácticas centralizadoras y la implantación de una política de mercado con tendencia a la privatización, lo que redefinió las directrices para los derechos sociales básicos, tales como salud y educación. La propuesta de Hayek fue articulada a la perspectiva económica del británico Keynes que proclamaba que el Estado debería extender algunos derechos sociales a los trabajadores, como salud, educación, infra-estructura y seguridad social, pero debería intervenir, administrar y gerenciar el mercado, teniendo como meta evitar nuevas crisis del sistema capitalista. Hayek y Keynes buscaron nuevas alternativas para evitar un colapso del capitalismo, derivado de problemas creados por la lógica de exclusión y concentración de la riqueza del mercado y las reivindicaciones de la clase trabajadora. Como adversarios del Estado Social, asumieron que era la hora y el turno del neoliberalismo.

El neoliberalismo surge como un movimiento ideológico, a escala verdaderamente mundial, como el capitalismo jamás había producido en el pasado. Consolida un cuerpo de doctrina coherente, autoconsciente, militante, lúcido y orgánicamente decidido a transformar todo el mundo a su imagen, en su ambición estructural y su extensión a nivel internacional. (ANDERSON, 1995, p. 22). Como ideología, el neoliberalismo se configura como aquel contenido de pensamiento que busca dar sustento y legitimación teórica a las prácticas efectivamente implementadas en la conducción de la vida real de las sociedades que viven sobre el modo de producción capitalista hegemónico, y que hoy pasan por intensos y extensos procesos de globalización cultural.

Históricamente, las décadas de 1970 y 1980 marcaron un ascenso del capitalismo neoliberal, iniciando un agitado período de re-estructuración económica, de reajustes sociales y políticos, y de nuevas decisiones gubernamentales. A partir de entonces, como en toda experiencia neoliberal, se iniciaron las políticas de privatización y tercerización o subcontratación, que en la visión neoliberal transforman los servicios en más eficientes y más productivos y, por lo tanto, menos onerosos. También se inicia el derrocamiento de los derechos de los trabajadores. La intervención en las empresas, así como en los servicios públicos en general, incentivó a la sociedad a aumentar el consumo ilimitado, ampliando los intereses privados del mercado, lo que llevó a un aumento significativo del papel de las ciencias y de la tecnología en el proceso de producción.

Se sustentaba un discurso vinculado a la necesidad irrefutable de las reformas neoliberales, dando inicio a una nueva forma de regulación - la acumulación flexiblecomo una forma de garantizar las estabilidades monetarias, políticas y democráticas para los países, inclusive los de América Latina, que recibieron serios impulsos neoliberales al final de la década de 1980. A partir de entonces, se consagró un nuevo papel del Estado: por un lado, el de la desregulación, y, por otro, el de la regulación, conforme determinaciones del Banco Mundial, que siempre actúa sobre las condicionalidades impuestas por el FMI. 
A América Latina le fue impuesto un conjunto de medidas de carácter neoliberal destinadas a promover una política de ajuste estructural y de recorte de gastos a los países endeudados, como en el caso de Brasil y Argentina. Las medidas implementadas, en acuerdo con las directrices neoliberales, además de minimizar el papel del Estado, buscaron fortalecer la iniciativa privada, contribuyendo directamente al sostenimiento de la desigualdad social, pues siguiendo el análisis de Cosmo y Fernandes (2009, p.7), se mantuvieron los privilegios de la élite y el tratamiento asistencialista de las masas - lo que las "aprisiona a los gobiernos neoliberales".

A partir de la década de 1990, siguiendo el análisis de Orso (2007), aunque la capacidad de influenciar a personas y grupos sea desigual en los flujos de la política global neoliberal, las reformas aplicadas a los diferentes países de América Latina, fueron semejantes y homogeneizadoras. Nuevos gobiernos reformistas pasaron a aplicar las orientaciones de los reajustes sociales y políticos, agravando el ciclo de subordinación de los países de América Latina, a los intereses de los reformadores empresariales (LAGOA, 2019; FREITAS, 2012).

El conjunto de transformaciones formó parte de un proceso de convergencia mundial y regional caracterizado por la adopción del esquema norteamericano de organización de las políticas. Según Shugurensky (1998, p. 125), un buen ejemplo de sistematización de los cambios es el caso específico de la educación superior. Para él "la convergencia no significa que todos los sistemas de educación superior se conviertan en uno solo, sino más bien que son gobernados en forma creciente por presiones, procedimientos y patrones organizacionales similares". El mismo autor sostiene que fue el resultado de un doble fenómeno de consenso y coerción en el que intervinieron actores sociales concretos en el contexto de tradiciones y culturas de los sistemas de educación superior que explican las particularidades y la organicidad de las reformas neoliberales.

Como mostró Shugurensky (1998), en el caso específico del campo educacional, la fuerza de la política neoliberal transfirió "naturalmente" para la educación los referenciales de la economía de mercado. Ésta deja de ser considerada como un derecho social y pasa a ser más una mercancía a ser procesada y desarrollada en el libre juego del mercado. Libâneo $(2003$, p. 92) añadió que actualmente la educación se organiza sobre el "paradigma de la libertad económica, de la eficiencia y de la cualidad", que se vale del individualismo, la competitividad y el mérito.

La estrategia neoliberal para cambiar el sistema educacional de América Latina tiene como su principal influyente político a la UNESCO. Como analizó Manacorda (2002, p. 353), en teoría se propone "ayudar a las asociaciones 'no gubernamentales' en la realización de programas educativos y en el enlace con las 'comisiones nacionales' que cada Estado-miembro de la ONU se esfuerza por establecer". Como resultado de esta demanda se fortalece el desarrollo de la política neoliberal, sobre todo por despegar la responsabilidad del Estado en relación a las políticas sociales de educación, como se ha dicho, transfiriéndola a la sociedad civil. Fue Gentili $(2001$, p.29) quien alertó que los socios de la UNESCO, el Banco Mundial y el Banco Interamericano de Desarrollo, "no se limitaban a desempeñar las tareas propias de simples agencias de crédito, sino que ejercían una función político-estratégica fundamental en los procesos de ajuste y re-estructuración neoliberal que se estaban llevando a cabo en nuestros países".

Asimismo, siguiendo el análisis de Gentili (1998), el Banco Mundial, el Banco Interamericano de Desarrollo y el FMI tuvieron un papel importante en el planeamiento y 
en la realización de las políticas sociales en América Latina, las cuales seguirán un principio básico con dos prácticas: la primera, el control de la calidad, realizado por medio de constantes evaluaciones y, la segunda, la articulación/subordinación del sistema educacional a las necesidades del mercado de trabajo. Esa segunda práctica da sentido a las políticas educacionales implantadas en América Latina (GENTILI, 1998).

Los nuevos criterios normativos neoliberales fueron apoyados por el gobierno argentino en el proceso de reforma o "modernización" para promover diversas transformaciones en el momento de su formulación e implementación. Al dar forma a las principales líneas de reforma, un grupo de expertos en educación y académicos colaboraron a través de su participación en el Consejo Nacional para la Educación Superior, un órgano asesor, en la definición de líneas de cambio, algunas de las cuales se expresaron, por ejemplo, en la Ley de Educación Superior $N^{\circ} 24.521$ promulgada en julio de 1995 en Argentina (FANELLI, 1997). Aquella política impulsada por el Ministerio de Cultura y Educación a través de la creación de la Secretaría de Políticas Universitarias (SPU) remite a los principios de transformación considerados por el Banco Mundial en "Lecciones de experiencia" y que se retoman en el Programa de Reforma de la Educación Superior (PRES), cuyo objetivo era promover la diferenciación de las instituciones mediante el fomento de la creación de universidades privadas; proporcionar incentivos a las instituciones públicas para diversificar sus propios recursos, incluida la calificación y vinculación del financiamiento con el desempeño; redefiniendo el papel del gobierno y la educación superior; e introducir políticas que den lugar a una mayor equidad. (KROTSCH, 2002) Según Krotsch "la adopción de los principios, la puesta en marcha de muchos de los proyectos por decreto y la promesa de una ley permitió a la SPU consensuar el programa de reforma y acceder a fondos ( 160.000 .000 de dólares) para los distintos proyectos con lo que pudo desplegar la política". (KROTSCH, 2002, p. 162)

Las reformas neoliberales encuentran su justificación en un diagnóstico previo que las autoridades y especialistas técnicos de organizaciones multilaterales hicieron sobre el funcionamiento general del sistema educativo latinoamericano. El diagnóstico apoyó el proceso de reformas educativas que se desarrolló y se está desarrollando rápidamente en Brasil y que fue más lento y resistido en Argentina a partir de la influencia de los discursos críticos en el país sobre los cambios generados. Algunas de las iniciativas, incluso que formaron parte de la Ley de Educación Superior, no se desarrollaron por la fuerte resistencia de los actores del sector educativo que cuestionaron las políticas gubernamentales, como es el caso de la evaluación y la acreditación universitaria, donde no llegó a crearse un mercado de servicios de evaluación a pesar de su previsión en la legislación señalada.

\section{NOTA 2: AGUDIZACIÓN ULTRA NEOLIBERAL EN EDUCACIÓN Y EN LA FORMACIÓN DOCENTE EN AMÉRICA LATINA}

La agudización de las políticas ultra neoliberales (ORSO, 2007, p. 177) configura la fase más perversa del neoliberalismo, centrada totalmente en el mercado, al punto de negar derechos humanos y a imponer un proyecto de sociedad en el que no hay lugar para la inclusión y la justicia social; tiene como objetivo la apertura a nuevos frentes de 
expansión del capital. Por lo tanto, la estrategia neoliberal alcanzó a América Latina, implantando reformas a través de una gran variedad de regulaciones, proyectos y programas, inclusive en la revisión completa de los sistemas educativos latinoamericanos.

En las últimas décadas del siglo XX, los Estados de América Latina se insertaron en los movimientos más amplios que buscaron la posesión de un poder intrínsecamente ligado a la dinámica del capitalismo, cuyo modo de producción material y de regulación cultural se hicieron presentes, asumiendo nuevas formas de represión. Así, la embestida neoliberal posiciona a América Latina en el proceso de globalización que comienza inicialmente en la esfera económica, pero luego se expande también para las demás dimensiones de la actividad humana incluyendo todos los sectores de vida social.

Eso significa que las élites responsables por la gestión político-administrativa de los países latinoamericanos rearticularon sus alianzas con socios extranjeros, invirtiendo en su inserción en el orden mundial, diseñada por el modelo de globalización neoliberal. De acuerdo con ese modelo, la administración debe ser orientada por las fuerzas de la propia sociedad civil y no más por la administración a través del Estado. Las leyes generales son aquellas de la economía de mercado y no de la economía política, y el mercado se regula por las fuerzas competitivas nacidas en los intereses de los individuos y grupos que se sectorizan dentro de la sociedad civil. Se entiende que el motor de la vida social es el mercado y no la administración política, luego la organización económica implanta un clima político de abandono interno y dominación externas internacionales, más allá de imponer una configuración socioeconómica, en la cual las condiciones de vida de la mayoría de la población se tornan cada día más precarias. Estos aspectos pueden ser mejor comprendidos a partir de ejemplos de las experiencias brasileña y argentina.

La acción "ultra neoliberal" fue totalmente fortalecida en América Latina. Particularmente en Brasil, la embestida neoliberal, fue bastante agravada después del golpe contra la Presidente Dilma Roussef, y aún más exacerbada después de la victoria de Jair Bolsonaro. El proceso siguió otros ejemplos mundiales como: los de Estados Unidos, con las victorias de Trump, Italia con Salvini, Hungría con Orbán y Filipinas con Duterte, casos que a pesar de que se registran en un movimiento mundial de fuerzas antiemancipatorias, antidemocrático, antifeminista, racista, antiecológico, pro-capitalista, no se distancian de lo que ocurre en el contexto brasileño que también destaca el tema de sus costumbres, de la moral y su interpretación religiosa, presentadas como cuestiones decisivas, casi pilares, de la visión del gobierno bolsonarista, reformista y fundamentalista.

Con el gobierno de Bolsonaro hubo una embestida reformista que implicó la tutela de una nueva regulación de la educación brasileña. La definimos como una acción destructiva que implanta ostensiblemente formas de control que buscan mantener el campo educacional en conformidad con el mercado educacional.

El conjunto de orientaciones neoliberales del gobierno brasileño actual también interfirió en la formación docente, tanto en la formación inicial como en la formación continua (BRZEZINSKI, 2007; 2009). En atención al mercado de trabajo que pasó a exigir formación rápida de profesionales, los cursos de licenciatura tuvieron que ser readaptados, lo cual significa que tendieron a la misma instrumentalización y capacitación exigida para el ejercicio técnico, como cualquier otra función (SCHEIBE, 2008). Ese aspecto es emblemático de la nueva lógica impuesta a la función docente que, posteriormente, se materializará en nuevas formas de actuación pedagógica. Esto no es diferente en América 
Latina donde, siguiendo a Neves $(2004,2013)$, se instituye en la formación de profesores una dirección que se encamina hacia la efectivización de la Pedagogía de la Hegemonía. Alude a un aspecto confirmado por Saviani $(2007$, p. 429) que denomina él “Pedagogía de la Exclusión", la cual trata de

preparar a los individuos para que mediante sucesivos cursos de los más diferentes tipos, se tornen cada vez más empleables, buscando escapar a la condición de excluidos. Y, en caso que no lo consigan, la pedagogía de la exclusión les terminará enseñando a introyectar la responsabilidad de esa condición (SAVIANI, 2007, p. 429).

La formación de profesores, en la reconfiguración sufrida gradualmente, mantiene el mismo lema en América Latina de "aprender a aprender" asumido como matriz pedagógica que se encuentra presente en documentos oficiales como el "Informe Jacques Delors", Educación: un tesoro a descubrir, publicado por la UNESCO en el año 1996. Aprender a aprender pasa a ser sinónimo de necesidad del individuo de estar constantemente aprendiendo cosas nuevas, en innumerables espacios, lo que descentra la función educativa y formativa que, prioritariamente, cabría en educación.

La propuesta consolida en la formación de profesores de América Latina, la teoría del profesor reflexivo, la cual destaca la importancia de reflexionar sobre la práctica cotidiana, mientras desvaloriza la adquisición de presupuestos teóricos. Al retirarse la base teórica de la formación docente, el profesor se transforma en un mero técnico ejecutor, responsable del adoctrinamiento a través de la educación. Cabe a esta convicción, el entrenamiento para la eficacia en el mercado de trabajo. Gentili desde 1998 alertó el hecho que "después del diluvio neoliberal", las escuelas serían mucho peores de los que han sido hasta ahora. En aquel momento él anunció un futuro que ya se hace presente: la educación y la formación de profesores de América Latina ya se encuentran sobre la égida del mercado, y el economicismo también se coloca encima de la política y de los derechos sociales (GENTILI, 1998, p. 33).

Los cambios impuestos a la educación y a la formación de docentes en América Latina se agudizaron en la década de 1990. En el caso de Brasil hubo una aprobación de la Ley de Directrices y Bases de la Educación (LDB/1996), lo que suscitó una gran variedad de reglamentaciones, proyectos y programas, como:

Educación para todos; el Plan Decenal de Educación, los Parámetros Curriculares Nacionales y las Directrices Curriculares Nacionales para la educación básica, la educación superior y la formación docente; el Sistema de Evaluación Nacional para la Educación Básica (SAEB), un plan denominado Examen Nacional de Cursos que evalúa diferentes cursos universitarios por medio de un examen para graduados; un Examen Nacional para concluir el Nivel Medio; la municipalización de los años iniciales de la educación fundamental; el Fondo de Manutención de Desarrollo de la Enseñanza Fundamental y la Valorización de la Docencia y la ley de Autonomía Universitaria (BEECH, 2009, p. 35). 
De modo semejante, en la Argentina se aprobó la Ley de Transferencia de los Servicios Educativos (1992) y, un año más tarde, la Ley Federal de Educación (LFE/1993) que lanzó la "refundación" del sistema educativo argentino. Además de eso fue

\begin{abstract}
sancionada la Ley de Educación Superior; fue restituido el Consejo Federal de Educación; fue firmado el Pacto Federal Educativo; y la estructura del sistema educativo argentino fue transformada en su totalidad - tradicionalmente estaba dividido en una educación primaria de siete años y una educación secundaria de cinco años. También fueron establecidos varios programas como el Sistema Nacional de Evaluación Educativa (SINEC), la Comisión Nacional de Evaluación y Acreditación Universitaria (CONEAU), el Pacto Social Educativo, la Red Federal de Formación Docente Continua, así como Contenidos Básicos Comunes para la Educación Pre-escolar, la Educación General Básica, el Polimodal (educación secundaria) y la Formación Docente (BEECH, 2009, p. 35).
\end{abstract}

La legislación de ambos países es un ejemplo de cómo se operó el proceso de legalización y formalización de las deliberaciones neoliberales, y es emblemático cómo ambas legislaciones manifiestan contradicciones - representan anhelos en el área educacional, al mismo tiempo que sufren cambios que representan el mantenimiento de un carácter eminentemente pragmático que se busca aplicar a la educación pública nacional. Para efectivizar los cambios los agentes de los sistemas se valen de un discurso justificado por una fuerte argumentación, orquestada por intelectuales y es ampliamente divulgada por los medios de comunicación, dirigidos a las subjetividades de las personas, convenciéndolas de sus verdades, de su pertinencia y de su indispensabilidad. Esta es la expresión ideológica del neoliberalismo que se presenta como fuerza de convencimiento de todas las sociedades históricas y de todas las personas de que tal concepción de realidad humana es la única posible, y, por lo tanto, el único camino verdadero, no habiendo otro para la conducción de la historia humana.

Esta influencia hace que los países se esfuercen para seguir las orientaciones de la Comisión Económica para América Latina (CEPAL), la Organización de las Naciones Unidas para la Educación, la Ciencia y la Cultura (UNESCO), del Banco Mundial y de la Organización para la Cooperación y Desarrollo Económico (OCDE). La visión de la CEPAL/UNESCO, por ejemplo, considera que los cambios globales serán rápidos y profundos por lo cual requieren que "la educación, más que adaptarse al presente, deba anticipar el futuro" (BEECH, 2009, p. 36); la visión de la Organización para la Cooperación del Desarrollo Económico (OCDE) juzga que es más importante identificar nuevas políticas educativas que estén "más allá de las políticas y del pensamiento actual de los países" de América Latina; el Banco Mundial, procura identificar los nuevos desafíos introduciendo reformas ligadas a las transformaciones en el financiamiento y en la administración de la educación. Finalmente, aunque presentan especificidades, todas las organizaciones citadas comparten visiones muy semejantes, acerca do que implica estar bien formado para el siglo XXI.

En lo que respecta específicamente a la cuestión docente, los organismos multilaterales señalan la necesidad de fortalecer su formación, a partir de diversos aspec 
tos: realización de revisiones y fortalecimiento de los planes y programas de formación docente; implementación de políticas de asesoría y capacitación docente; implementación de mecanismos de evaluación y reconocimiento del desempeño docente. "Recomendaciones" que durante los años noventa exigieron, a la mayorías de los gobiernos de América Latina, invertir en el perfeccionamiento, la actualización, el control, la evaluación y reconversión de los docentes, buscando normalizar y adecuar sus habilidades y competencias, de acuerdo a las exigencias planteadas.

En general, la lógica hegemónica neoliberal impuso en la formación docente de América Latina, la exigencia de cambios en el perfil de los docentes, tanto en el plano colectivo como en el individual, la cual debería posibilitar la plena liberación de las capacidades para conducir todas sus iniciativas, pero basadas sólo en las del mercado, cualquiera fueran sus esferas de conducta. Como consecuencia, los cursos de formación de profesores se ajustaron a los procesos de flexibilización, convirtiendo al profesor, en la mayoría de los casos, en un sujeto adaptable al mercado.

Lagoa (2019) sostiene que "el principio de la flexibilidad" revela "la tentativa de hegemonización de un determinado sentido de currículo en Educación" para América Latina. En este sentido, como los valores de la sociedad capitalista son incorporados a la formación docente, se amplía la exigencia de que estos pasaron a permear la actividad educativa, correspondiendo a los profesores ocuparse de ajustar la función social de la escuela dentro del capitalismo.

Esto también explica por qué los profesores latinoamericanos ocupan un lugar de centralidad en las políticas educacionales neoliberales: a ellos les cabe "promover la aceptación pasiva de las contradicciones inherentes al sistema, construyendo una subjetividad entre los individuos que legitima ese orden social" (LAGOA, 2019, p.11). Cabe señalar que, finalmente, el conjunto de las reformas de los cursos de formación docente agravo la situación de los profesores en la región latinoamericana.

NOTA 3: FORMACIÓN DE PROFESORES BRASILEÑOS Y ARGENTINOS EN LA AGUDIZACIÓN ULTRA NEOLIBERAL

La agudización ultra neoliberal que arrasa la formación de profesores brasileños se asocia a los impactos de los ataques realizados por el gobierno Bolsonaro a la educación pública y, particularmente, a la universidad pública. En particular el ataque se expresa en una "demonización" de los profesores de las universidades públicas que sufren con las demandas de modificación de su función social.

En el actual momento histórico, en Brasil se han confirmado iniciativas legales que conducen la educación hacia dos grandes vertientes: una, destinada a preparar a las nuevas generaciones provenientes de la elite social, para que puedan continuar la gestión de los negocios e intereses, manteniendo los privilegios de las clases dirigentes; otra vertiente destinada a las nuevas generaciones de clases de trabajadores para continuar actuando como mano de obra técnica en los diversos niveles a fin de garantizar la producción y los bienes para el mercado. En función de las recientes directrices legales que hacen visibles las contradicciones entre las exigencias pensadas para la educación, en cuanto humanizadora y concientizadora, y los sesgos presentes en la realidad social y 
emergentes de la política educacional del estado brasileño, elegimos la discusión sobre el Programa "Escuela Sin Partido que debe ser leído en conjunto con otras medidas como: la Enmienda Constitucional 95, la Reforma de la Enseñanza Media, la nueva Base Nacional Común Curricular (BNCC), y la Base Nacional Común de la Formación de los Profesores de la Educación Básica - BNCFP (BRASIL, 2018), que personalizan los principales desafíos puestos a la educación y a la formación de profesores brasileños. Entendemos que en contraposición a las normativas anteriores, las actuales imponen la opresión, la degradación y la alienación de las esferas de la existencia de la vida, borrando la humanización como horizonte de la educación.

El proceso de agudización neoliberal sobre la educación y la formación docente es personificado por el Programa Escuela Sin Partido, el cual concretiza las estrategias de gobierno brasileño para silenciar voces contrarias a la ideología conservadora vigente.

El Programa Escuela Sin Partido fue una propuesta reformista/oportunista denominada en los medios académicos como "Ley de Mordaza", sancionado por el Proyecto de Ley $867 / 2015$, cuyo programa incluye las directrices y bases de la educación nacional. Destacamos el siguiente fragmento de texto

\footnotetext{
Art. $2^{\circ}$. La educación nacional atenderá a los siguientes principios:

I- Neutralidad política, ideológica y religiosa del Estado;

II - Pluralismo de ideas en el ambiente académico;

III - Libertad de aprender, como proyección específica, en el campo de la educación, de la libertad de conciencia:

IV - Libertad de creencia;

V - Reconocimiento de la vulnerabilidad del educando como parte más débil en la relación del aprendizaje;

$\mathrm{VI}$-Educación e información del estudiante en cuanto a los derechos comprendidos en su libertad de conciencia y de creencia;

VII - Derecho del país a que sus hijos reciban la educación moral que esté en todo de acuerdo con sus propias convicciones (BRASIL, 2015e, El énfasis es añadido).
}

El Programa impone la bandera de "neutralidad política" a la educación, defiende un posicionamiento político-partidario implícito que actúa en el silenciamiento de la pluralidad de ideas, el pluralismo de pensamiento y el diálogo, lo cual resulta totalmente perjudicial para la educación, los profesores y los estudiantes. Impone silencio a los interlocutores del proceso educacional, negando posibilidades de diálogo, así como de autonomía y de crítica, en cuantos aspectos necesarios y fundamentales al protagonismo de la educación. Al decretarse el fin del derecho a la libre expresión se cercena también un presupuesto básico de la democracia, aunque la censura previa va en contra del derecho de libre expresión consagrada en la Constitución Federal Brasileña de 1988, artículo 206 de la CF/1988: "Il - libertad de aprender, enseñar, investigar y divulgar el pensamiento, el arte y el saber; III - pluralismo de ideas y de concepciones pedagógicas, y coexistencia de instituciones públicas y privadas de enseñanza" (BRASIL, 1988).

La Enmienda Constitucional n. 95 (EC 95), de 15 de diciembre de 2016, impuesta a partir de 2018 y que tendrá vigencia hasta el año 2036, efectuó un cambio constitucional que instituye un Nuevo Régimen Fiscal (NRF) en el país, divide el presupuesto de la Unión en partes independientes, siendo una la del Poder Ejecutivo que incluye al Ministerio de Educación (MEC). El nuevo régimen fiscal y el presupuesto del Poder Ejecutivo no podrán 
ser reajustados con porcentajes arriba de la inflación del año anterior. Eso significa que se han congelado los gastos públicos de la educación brasileña, ipor 20 años!

La EC 95 se configura como estrategia del gobierno brasileño que va en contra del Plan Nacional de Educación PNE (2014-2024), aprobado por la Ley № 13.005, de 24 de junio de 2014. El PNE establece metas que para ser atendidas exigirán substancial elevación del volumen de recursos financieros aplicados a la educación. Entre tanto, la EC 95 basada en la estructura capitalista, al reducir las inversiones en áreas primordiales como la educación, intensifica la entrada de empresas privadas en ese sector, lo que es bastante deseado por el sistema actual.

Más allá de la pérdida de recursos para el financiamiento de la educación, los brasileños todavía reciben amargamente otros aspectos con la imposición de la EC 95 , como:

\begin{abstract}
la reforma laboral con la pérdida de derechos para los empleados/as, la reducción drástica del financiamiento para la adquisición de casas populares (Mi, Mi Vida), la reducción de la Bolsa Familia, el estancamiento de la Reforma Agraria, la Intervención Militar en Río de Janeiro, la propuesta de Reforma Previsional, la inseguridad energética, el aumento de la mortalidad infantil, entre otros aspectos, son parte de un paquete de políticas comprometidas con la concentración de la riqueza y el aumento de la pobreza con la retirada de derechos de los trabajadores (CURY; REIS; ZANARDI, 2018).
\end{abstract}

Asociada al itinerario de la agudización neoliberal, la EC 95 muestra el ascenso ideológico del gobierno actual que responde "a los anhelos de los mercados, usurpando a la sociedad brasileña y al Parlamento la prerrogativa de definir la forma del presupuesto destinado a áreas como educación, salud y asistencia social" (GOMES, 2019, p. 183). Dada nuestra condición histórica de opresión, degradación y de alienación, la EC 95 es más una expresión del poder que atraviesa lo social para consolidar y reforzar la deshumanización de lo público, del mundo del trabajo y de la alienación del universo de la cultura. Destituir la educación de su más profunda razón que es ser práctica y vía de emancipación.

La política reformista autoritaria del actual gobierno brasileño - Bolsonaro, continúa con el derrocamiento de los derechos del pueblo brasileño, modificó la Ley de Directrices y Bases de la Educación Nacional, Ley 9.394 / 1996 (LDB / 1996), por ejemplo, cambiando la concepción educación pública de calidad gratuita y calidad social incluida en el documento, abriendo posibilidades para consolidar la caracterización errónea de la educación pública orientada al mercado. La alteración en la LDB/1996 permitió la Reforma de Enseñanza Media, provocando el vaciamiento de su currículo obligatorio e instituyendo itinerarios formativos que fragmentan y acentúan la dualidad curricular estructural de la enseñanza media. Consecuentemente, mantienen la distinción entre escuelas para la clase trabajadora y para la clase dominante en el país, configurando un cambio que está en línea con los intereses del capital financiero privado, imponiendo una lógica formativa debilitada en la escuela secundaria, dirigiendo la preparación de mano 
de obra para satisfacer las demandas momentáneas y puntuales del mercado laboral, como ocurre con la formación docente actual.

En contramano del movimiento de las entidades científicas y sindicales, la Base Nacional Común Curricular (BNCC, 2015-2018), en el contexto de la Reforma (2017), tiene tres canales principales de participación establecidos por el MEC: página electrónica, audiencias públicas y seminarios, no habiéndose atendido efectivamente las demandas de la sociedad civil. Por lo tanto, la convergencia política en torno de la BNCC en las últimas décadas, no determina la legitimidad del proceso de elaboración e implementación del documento final, como consecuencia de la resistencia legítima de algunos sectores de la sociedad que no se sienten representados en el proceso. Así es que las primeras tensiones en torno a la BNCC no se remiten a la falta o al cuestionamiento de la previsión legal, sino más bien en cómo llevar a cabo la alineación necesaria entre lo que se está utilizando en educación y su historia local y regional de reflexión y logros, y lo nuevo instituido por la ley a nivel nacional. Además, la BNCC se constituyó como un documento normativo de carácter prescriptivo y de alcance nacional, superponiéndose a los documentos curriculares de estados y municipios. Se trajeron rumbos pragmáticos a la educación a partir del discurso sobre la promoción de la "igualdad en la educación brasileña"; sin embargo, se establece un currículo básico común que deberá ser estandarizado para todas las escuelas del país.

En la línea de la agudización neoliberal, el 22 de diciembre de 2017, el Ministerio de la Educación publicó la Resolución CNE/CP no 2 que refrendó la nueva Base Nacional Común de la Formación de los Profesores de la Educación Básica - BNCFP (BRASIL, 2018), una política que promueve alteraciones significativas para la educación $y$, consecuentemente, para los docentes.

La Resolución no fue discutida con las instituciones responsables de la formación de profesores, reiterando el carácter autoritario y arbitrario del gobierno actual. También desconsideró la existencia de las Directrices Curriculares Nacionales para la formación inicial en el nivel superior (cursos de licenciatura, cursos de formación pedagógica para graduados y cursos de segunda licenciatura) y para la formación continua anterior, firmando la Base Nacional Común de la Formación de los Profesores de la Educación Básica -BNCFP (BRASIL, 2018) más como una "imposición continua de políticas sin debate" del gobierno reformista. (2018):

Apoyamos la crítica elaborada por Freitas (2019a; 2019b) que reputó la BNCFP

EI MEC otra vez más coloca unilateralmente el énfasis en un nuevo documento sin cualquier consulta o escucha a la comunidad escolar, a los investigadores, a las escuelas y a las universidades. ¿Nuevas directrices de formación de profesores?, ¿Nuevas para quién? ¿EI MEC sabe que las DCN para formación de profesores de 2015 fueron ampliamente discutidas y aprobada por el CNE con amplio debate con todos los sectores de la sociedad? (FREITAS, 2018).

La Base Nacional Común para la Formación de Profesionales de la Educación Básica (2018), siguió el mismo recurso ideológico, y cambia nuevamente los rumbos de la formación docente. En su versión preliminar, el Ministerio de Educación y Cultura 
presentó al Consejo Nacional de Educación (CNE) un documento que generó manifestaciones de diferentes entidades contrarias a la revisión de las Directrices Curriculares Nacionales para la Formación Inicial y Continua en el Nivel Superior de Profesionales del Magisterio para la Educación Básica (DCN's, 2015). El documento exigió promover nuevas estrategias de formación nacional de profesores, fomentando en diciembre de 2018, alteraciones significativas en las DCN's (2015), principal regulación de la formación inicial y continua de docentes brasileños, la cual pasó a sustentar una concepción de formación basada en el análisis de la Organización para la Cooperación del Desarrollo Económico (OCDE)'.

Voces de resistencia se levantaron en Brasil, la nuestra entre ellas, para abogar que aunque el epicentro de la BNCFP (2018) haya sido la Base Nacional Común Curricular (BNCC, 2018), el que sea considerada una exigencia del sistema educacional brasileño, que remonta al CF/1988, la Ley de Directrices y las Bases de la Educación Nacional (BRASIL, 1996), las Directrices Curriculares Nacionales Generales de la Educación Básica (BRASIL, 2009) y el Plan Nacional de Educación (BRASIL, 2014), su previsión legal, y también su convergencia política en torno al BNCC, eso no determina la legitimidad del proceso de su elaboración e implementación en el país (CURY; REIS; ZANARDI, 2018).

La Asociación Nacional de Investigadores en Educación (ANPEd) (2019a; 2019b; 2019c), por ejemplo, como representante del movimiento de educadores y entidades científicas del área educacional, publicó un documento posicionándose contrariamente a la versión preliminar de la Base Nacional Común para la Formación de Profesionales de la Educación Básica (BNCFP), afirmando que evidenciaba la tendencia del MEC en proseguir formateando la educación brasileña, yendo en contramano de las preocupaciones explicitadas por el movimiento (ANPED, 2019).

Nuestra evaluación crítica, en compañía de Gomes (2019, p.207), sustenta que "la BNCC y la BNCFP no mantienen solamente relaciones didáctico-pedagógicas entre sí, mantienen también la coherencia interna que se espera entre instrumentos de una política de educación nacional". Ambas representan una gran red de intereses muy bien articulados y conectados al poder económico, político y cultural. Se trata de políticas educacionales fragmentadas que revelan su énfasis tecnicista en la alteración de las currícula, priorizando el desarrollo de las competencias, considerado imprescindible para el acceso al mundo del trabajo. Frente a la estructura socio-política que continúa imponiendo golpes reformistas a la educación brasileña y a la formación docente, el mayor desafío nos parece que es buscar superar el escepticismo y la frustración, rescatar el saber y el colectivo de profesores, como acción de resistencia y militancia contra hegemónica, como un modo de contribuir a la construcción de una contra-ideología.

\section{NOTA 4: FORMACIÓN DE PROFESORES ARGENTINOS EN LA AGUCIZACIÓN ULTRA NEOLIBERAL}

Históricamente, la institucionalización de la formación docente en la Argentina ocurrió al final del siglo XIX, dentro del proceso de expansión y desarrollo del sistema de educación e instrucción pública. La creación y expansión de instituciones especializadas para la formación de maestros y profesores fue generada por el propio Estado, el que 
también definió las características de la formación, las formas de ingreso y de acceso al ejercicio de la docencia.

El sistema formador de la Argentina tiene características peculiares, se inició en las Escuelas Normales, de nivel medio creadas a partir de 1870 y, un siglo más tarde, fueron convertidas en Escuelas Normales Superiores, pasando a constituirse como instituciones de nivel superior no universitario. Rojas (2012) explica que, a partir de las Escuelas Normales, también surgieron las escuelas de comercio e industrias, en 1890, y los Seminarios Pedagógicos que formaban profesores para la enseñanza secundaria, en 1903.

El autor afirma que durante el gobierno peronista

\begin{abstract}
fueron implementadas otras instituciones de carácter terciario orientadas a la formación profesional. Con la transferencia de formación de profesores de nivel medio al superior, en 1970, la mayoría de las Escuelas Normales se transformaron en Institutos Superiores de Formación Docente, bajo la dependencia del estado nacional, y las jurisdicciones provinciales o de gestión privada (ROJAS, 2012, p.2-3).
\end{abstract}

A lo largo del tiempo coexistieron diversos tipos de instituciones formadoras en el país: "Escuelas Normales, Institutos de Enseñanza Superior, Institutos Provinciales de Formación Docente, Institutos Terciarios de Formación Docente y Técnica, y Universidades", las cuales preparan, preferencialmente, profesores para el nivel medio y universitario (MARINO, 2019, p.3).

A principios de la década de 1990, la influencia neoliberal que se introduce en la Argentina pasó a seguir las directrices internacionales, lo que generó un contexto de reforma asociadas al posicionamiento del Estado de desregular, descentralizar y privatizar los servicios públicos, entre ellos la educación. Así como los demás países de América Latina, las políticas de formación fueron orientadas hacia el perfeccionamiento y actualización de los docentes.

Conforme analiza Puiggrós (2010), durante el gobierno de Carlos Menem (1989/1999), se instituye una política educativa argentina cumpliendo la agenda del Banco Mundial. La Argentina pasó a considerar la educación como un elemento del mercado regulado por la oferta y la demanda, y no como un bien social, como ya había ocurrido en Brasil.

El mismo gobierno pasó a dotar de estrategias para la re-estructuración del sistema de formación docente, sin promover debates sobre el papel del estado nacional en materia de formación docente y la integración del sistema formador (FELDFEBER, 2010). Por ejemplo, sancionó la Ley de Transferencias (1991) que mudó de la jurisdicción nacional las instituciones formadoras a las provincias y a la municipalidad de la ciudad de Buenos Aires. La Ley de Transferencias está compuesta por un conjunto de leyes y resoluciones del Consejo Federal de Cultura y Educación (CFCyE) que pasaron a atender las recomendaciones de organismos internacionales, constituyendo un cuerpo normativo que, aunque compacto, regula todos los niveles del sistema educativo argentino (MISURACA; MENGHINI, 2010).

Rojas (2012, p.112) complementa lo anterior afirmando que "la instauración de la Ley de Educación Superior en 1995 y los posteriores mecanismos de evaluación surgidos en esta reglamentación trataron de encauzar los sistemas de educación superior universi 
tario y no universitario (SU y SNU) dentro de ciertos límites de calidad y eficiencia, a fin de albergar en forma armónica a todas las instituciones del sistema". Siguiendo al autor, la Ley de Educación Superior, de 1995, todavía vigente, instituyó la Comisión Nacional de Evaluación y Acreditación Universitaria (CONEAU), que es un organismo descentralizado que funcionaba en jurisdicción del Ministerio de Educación, Ciencia y Tecnología (MECyT), escindido desde el 2007 en los ministerios de Educación y de Ciencia, Tecnología e Innovación Productiva (desde 2018 Ministerio de Educación, Cultura, Ciencia y Tecnología). La CONEAU es el organismo público nacional argentino de evaluación y acreditación universitaria, y su creación está en relación con la tendencia neoliberal en todo Latinoamérica del surgimiento de entidades de control, cuya creación formó parte de las "reformas financiero-dependientes" (CARNOY, 1999) dado que inicialmente contó con financiamiento del Banco Mundial para el desarrollo de sus actividades. La ley autoriza también, la creación de entidades privadas de evaluación y acreditación, reconocidas por el Ministerio de Educación, previo dictamen de la CONEAU, las cuales no prosperaron siendo la CONEAU la única agencia evaluadora en el sistema universitario.

El derrotero que siguió la LES (1995) en Argentina da cuenta del papel de los actores concretos y de las tradiciones educativas en la implantación de las políticas neoliberales. En efecto, la fuerte tradición de autonomía de las universidades públicas, heredera de la Reforma Universitaria de 1918, operó como un factor de resistencia decisivo que puso límites a la reforma de esta época.

Por un lado, no prosperó la creación de agencias privadas de acreditación prevista en la LES habiendo sido legitimada la CONEAU como organismo descentralizado que funciona en la órbita del Ministerio de Educación de la Nación para realizar las tareas evaluadoras, evitándose la creación de un mercado de servicio de evaluación. Esta aceptación fue el resultado de un fuerte proceso de resistencia y negociación entre los actores de las universidades públicas y el gobierno nacional de Carlos Saúl Menem, en la definición de un modelo de evaluación que era visto como un control externo y una invasión a la autonomía de las instituciones. Por otro lado, expresando mecanismos de resistencia, fueron introducidas dos modificaciones orientadas a garantizar la educación superior como un derecho y como un deber del Estado: la modificatoria $\mathrm{N}^{\circ} 25.573 / 02$ lo hace para facilitar el ingreso, la permanencia y la graduación de las personas con discapacidad y la modificatoria $\mathrm{N}^{\circ} 27.204 / 15$ que garantiza la gratuidad de los estudios de grado y el ingreso libre e irrestricto a las instituciones de educación superior de gestión estatal, al final del gobierno de Cristina Fernández de Kirchner.

Así como ocurrió en Brasil, en atención a los mandatos de los organismos internacionales, la Argentina implementó cambios en el sistema formador asumiendo un carácter instrumental, salvo excepciones, con el objetivo de ocultar la dimensión políticoideológica subyacente en los procesos de transformación neoliberales adoptados (MARIANO, 2019; OLIVEIRA; FELDFEBER, 2010).

A pesar del movimiento de resistencia y evaluación de las tendencias impuestas por el proyecto neoliberal implementado en la Argentina, después de los años noventa, algunas continuidades son detectadas, como las políticas de formación de profesores formuladas por el Consejo Federal de Cultura y Educación, las que se alinearon con el discurso de la calidad educativa, dígase neoliberal, enfatizando la evaluación y acredita 
ción institucional, como ocurrió en Brasil y en otros países de América Latina. En ese sentido, conforme enuncia Marino (2019), el Proyecto Educativo Institucional (PEI) de cada institución fue utilizado como instrumento para alcanzar la continuidad de la oferta académica, y la formación docente se orientó hacia la lógica impuesta, o sea, un profesor "aplicador" de estrategias para solucionar los problemas relativos al aprendizaje de los alumnos (MISURACA; MENGHINI, 2010). En el mismo sentido, la acción de la Red Federal de Formación Docente Continua impuso la capacitación de profesores con un carácter competitivo, basada en criterios mercantilistas, aspectos que no se instituía totalmente en la Argentina, pero sí en toda América Latina.

Argentina tiene una reacción diferente a los demás países de América Latina que asumirán las políticas neoliberales en el nivel institucional. Según Misuraca y Menghini (2010) hubo consecuencias en la instalación de mecanismos competitivos y disciplinadores, característicos del pensamiento neoliberal y neoconservador, y de la lógica mercantil. Muchas manifestaciones hicieron frente a las contradicciones impuestas por las orientaciones socioeconómicas, destacando la coexistencia de tendencias tanto de continuidades, como de rupturas al respecto de las políticas hegemónicas de la década de 1990 en el país (FELDFEBER; GLUZ, 2011). La Ley de Educación Nacional № 26.206/2006 (LEN/2006), por ejemplo, puede ser asumida como acto simbólico de cambio en el campo educativo, frente al consenso reformista de los años noventa. La nueva ley promueve un diagnóstico sobre el sistema de formación docente, sobre: 1) fragmentación institucional, 2) falta de monitoreo y evaluación del sistema formador, 3) baja interrelación entre el sistema estatal y el privado, y 4) escasa información sobre las demandas del sistema.

La LEN/2006 crea el Instituto Nacional de Formación Docente (INFD) como un organismo regulador nacional de la formación docente. Éste tenía como atribuciones: 1) fortalecer las relaciones entre el sistema de formación docente y de otros niveles del sistema educativo; 2) reorganizar el sistema formador mediante la aprobación de lineamientos curriculares básicos para la formación docente inicial y continua; 3) estimular y desarrollar acciones de investigación y de desarrollo curricular en los institutos formadores; 4) coordinar acciones de acompañamiento y de evaluación de las políticas e impulsar acciones de cooperación técnica interinstitucionales e internacionales (Mariano, 2019). En lo que se refiere a la formación docente, la LEN (2006) buscó articular los niveles nacional, jurisdiccional e institucional, contando con la asistencia y el asesoramiento del Consejo Consultivo, compuesto por representantes del Ministerio de Educación, Ciencia y Tecnología, del Consejo Federal de Educación, del Consejo de Universidades, del sector gremial, de la educación de gestión privada y del ámbito académico (FELDFEBER, 2010).

Marino (2019, p. 6) analiza y sistematiza otros documentos oficiales que inciden directamente sobre la formación docente de la Argentina, tales como:

Resoluciones del Consejo Federal de Educación. La Resolución N.24/2007 traza los Lineamientos Curriculares Nacionales para la Formación Docente Inicial que consiste en una propuesta para discutir y mejorar las definiciones curriculares y, especialmente, fortalecer la integración nacional del currículum de formación docente, buscando asegurar niveles de formación y de resultados equivalentes en las distintas jurisdicciones, facilitar la movilidad de los alumnos durante su formación y garantizar el reconocimiento nacional de los títulos de los egresados. El documento es un marco 
regulatorio y anticipatorio de los diseños curriculares provinciales y de las prácticas de formación docente inicial, para todos los niveles y modalidades del Sistema Educativo Nacional. Éste refiere a la gestión y desarrollo curricular, apunta líneas para la capacitación y recomienda cuestiones relativas a la organización de la oferta de formación (ARGENTINA, 2007a). La Resolución № 30/2007, del Consejo Federal de Educación trata al Sistema de Formación Docente instituyendo, como su principal función, la contribución para la mejora de la educación argentina. Dentro de sus propósitos están la formación inicial, continua y la de producción de saberes sobre la enseñanza, la formación y el trabajo docente (ARGENTINA, 2007b). Esa Resolución amplía las funciones del Sistema de Formación Docente, incluyendo el asesoramiento pedagógico de las escuelas, la actualización de los docentes en ejercicio, la realización de investigaciones sobre enseñanza y sobre el trabajo docente y formación docente, la preparación para el desempeño de distintas funciones en el sistema educativo y la producción de materiales pedagógicos, entre otras (MARINO, 2019, p. 6).

Conforme al mercado educativo hay un conjunto de normas establecidas por el nivel central el cual prescribe funciones, responsabilidades y plazos de ejecución de las instituciones formadoras. No obstante, se garantizan formas que aseguren a las provincias el cumplimiento de la oferta de formación de profesores de acuerdo con las necesidades de cada jurisdicción en acuerdo a lo establecido en la Ley de Educación Nacional de 2006. Un ejemplo de acción es el del Instituto Nacional de Formación Docente (INFD) que presenta programas que muestran la construcción de acuerdos y el desarrollo de proyectos que son mediados por recompensas financieras, instituyendo la competencia entre pares.

Marino (2019, p. 7-8) completa el análisis afirmando que el

Consejo Federal de Cultura y Educación pasa a ser denominado Consejo Federal de Educación (CFE) (LEN/2006, art. 76) y sufre alteraciones en su constitución, contando con representantes de la educación de gestión privada y de organizaciones sociales vinculadas a la educación, lo que coloca al sector privado en las instancias decisivas de las políticas públicas. Hay, también, representantes de universidades privadas en el Consejo de Universidades, en el ámbito do Consejo Consultivo del Instituto Nacional de Formación Docente. El Instituto aglutina las regulaciones referentes a la formación docente y asegura el control de las acciones en este contexto, teniendo un carácter ejecutivo y verticalista, de acuerdo con la lógica de la "nueva gestión pública", que adopta tecnologías de gestión propias del ámbito privado.

Debido a que el INFD formula políticas para todas las instituciones formadoras del país, incluyendo a los institutos superiores y las universidades -públicos, privados, provinciales y nacionales- emergieron una serie de problemas en cuanto a la autonomía 
y la autarquía de las universidades nacionales, como ocurre actualmente en Brasil, conferida por la Constitución Nacional (art. 19), conforme argumentan Misuraca y Menghini (2010).

En el año 2010 el Consejo Interuniversitario Nacional (CIN) que agrupa a los rectores de universidades públicas, convocó a las Asociación de Facultades de Humanidades y Educación (ANFHE) -la conforman las unidades académicas que forman en carreras de humanidades y educación en universidades públicas- y al Consejo Universitario de Ciencias Exactas y Naturales (CUCEN) -integrado por decanos de unidades académicas de Ciencias Exactas y Naturales de gestión pública- para trabajar en una propuestas de acreditación de las carreras de profesorado de Biología, Física, Matemática, Química, Historia, Geografía y Letras. Como resultado de esta Comisión Mixta se elaboró el documento "Lineamientos básicos sobre formación docente de profesores universitarios" que fue definiéndose por etapas hasta llegar a su versión final en abril de 2011. No obstante, este proceso quedó inconcluso en tanto no se avanzó, como en el caso de otras carreras de interés público comprendidas en el artículo 43 de la LES que aprobaron sus estándares de acreditación y fueron evaluadas por la CONEAU. Por su parte la ANFHE también avanzó con un modelo de evaluación de los profesorados universitarios propio que dio cuenta del intento por alejarse de la impronta neoliberal con la que se definieron inicialmente los procesos de acreditación de carreras en el país. Así, entre los años 2015 y 2017, docentes, alumnos y egresados de las Carreras de Profesorado en Letras de cuatro facultades del país encararon procesos de autoevaluación institucional y curricular en el marco de una experiencia piloto promovida por la ANFHE. Desde una perspectiva innovadora se promovió una autoevaluación cuyos estándares se formularon colectivamente entre las distintas unidades académicas involucradas y el interior mismo de las carreras de Profesorado en Letras. Tuvo la particularidad de conformarse como un modelo alternativo de evaluación institucional que incluyó modalidades de investigación de carácter auto-evaluativo, cualitativo, democrático y participativo, centrada en el currículum de las carreras evaluadas, en las particularidades de cada unidad académica y en la construcción colectiva de conocimiento².

Asimismo, en 2009 fue aprobado por Resolución № 868 el Proyecto de Apoyo a las Ciencias Humanas (PROHUM) que significó un desembolso de 5.730 .325 pesos para financiar el mejoramiento de la calidad de la formación en carreras de Educación, Historia, Filosofía, Letras e Idiomas en las unidades académicas de las universidades públicas. A diferencia de las carreras acreditadas que han sido beneficiadas con el programa de mejoramiento específico destinado a implementar las recomendaciones surgidas de la evaluación llevada a cabo por la CONEAU, en este caso se trata de fondos otorgados a partir de la presentación y evaluación de proyectos estratégicos elaborados para el mejoramiento de la calidad de los profesorados mencionados. También aquí podría ser visto como una política gubernamental producto de la resistencia a las políticas neoliberales por cuanto el financiamiento no estuvo ligado a resultados de procesos específicos de evaluación y acreditación.

El Sistema Nacional de Formación Docente se organiza institucionalmente en todo el país respetando "los principios de integración federal y convergencia de las políticas jurisdiccionales con la política nacional" (ARGENTINA, 2008, p. 3). La administración del Sistema y de la responsabilidad es del Ministerio de Educación y de los poderes ejecutivos de las provincias y del gobierno de la Ciudad Autónoma de Buenos 
Aires. El Consejo Federal de Educación trata las políticas y estrategias de formación docente, mientras que la coordinación del Sistema queda a cargo del Instituto Nacional de Formación Docente (ARGENTINA, 2008). El Ministerio responsable de la educación en el nivel central y el Consejo Federal de Educación deciden sobre las políticas y los planes de formación docente inicial; los lineamientos para la organización y administración del sistema y de los parámetros de calidad que orientan los diseños curriculares; y las acciones que garanticen el derecho a la formación continua a todos los docentes del país, en todos los niveles y modalidades, así como la gratuidad de la oferta estatal de capacitación (art. 74) (ARGENTINA, 2006).

El art. $3^{\circ}$ da Resolución № 72/2008 prevé que la gestión del Sistema Formador Docente se organiza en cada jurisdicción educativa, como una unidad específica y que cuenta con una estructura orgánica - equipos técnicos, recursos de acuerdo a los planes de trabajo establecidos, e instancias que articulen políticas, acciones y proyectos de su competencia, en conjunto con las áreas de gobierno, instituciones de formación, universidades y organizaciones gremiales. Cada jurisdicción deberá garantizar la gestión del sistema formador -planeamiento, desarrollo, evaluación de las políticas, acompañamiento institucional y de vinculación con las escuelas, universidades y entorno social y cultural (ARGENTINA, 2008).

En la Ley Nacional de Educación Superior n. 24.521/1995, en el Título III, se establece que las provincias y la municipalidad de la Ciudad Autónoma de Buenos Aires son las responsables de la organización de la educación superior no universitaria, con normas para la creación, competencia, modificación y cierre de instituciones, así como el establecimiento de las condiciones de su funcionamiento. El Estado nacional podrá apoyar programas de educación superior no universitaria (ARGENTINA, 1995).

Uno de los problemas centrales que concierne a la formación docente en la Argentina se relaciona al sistema formador. Marino (2019) afirma que la transferencia de la educación superior a las provincias, en 1994, provocó la coexistencia de subsistemas con características divergentes, llegando a la situación de no reconocimiento de títulos expedidos en una jurisdicción por otra. La fragmentación no sólo sucede entre las provincias, también al interior de las instituciones, y entre las instituciones formativas (escuelas normales, institutos superiores, universidades, de dependencia estatal o privada). Todavía existe una formación del "funcionario de Estado" establecida por el modelo terciario, y la del "profesor universitario", que no siempre es un profesional de enseñanza. Por eso, Alliaud (2009) argumenta sobre la necesidad de procurar una articulación del nivel superior entre las universidades y los institutos de formación docente, conforme está previsto en la Ley de Nacional de Educación Superior No 24.521/95, para asegurar un sistema integrado de formación docente.

La articulación e integración del sistema formador, aproximando Universidades e Institutos Superiores de Formación Docente fue intentada en los años 2008 y 2009 con la promoción de Proyectos de articulación e integración de la formación docente (Resoluciones 113/08/Anexo e 563/09/Anexo), mas fue solamente con la Resolución No 140/2011, que trata los Lineamientos Federales para el planeamiento y la organización institucional del sistema formador, conforme explica Marino (2019, p. 13), que hubo un 
MAGALHÃES, S. M. O.; ARAUJO, S.; ARGÜELLO, S. B.

balance de las principales acciones desarrolladas desde la instauración del Plan Nacional de Formación Docente (CFE 23/07):

\begin{abstract}
a) la renovación de los diseños curriculares de formación docente de nivel inicial y primario con criterios nacionales y la elaboración jurisdiccional, superando la dispersión de los planes, duración y cargas horarias; b) la unificación de las nominaciones de títulos, pasando de más de 1.500 a 33 títulos válidos para todo o país; c) la generación de un proceso de Registro de Instituciones y Ofertas que precede el circuito de Validez Nacional; d) el fortalecimiento de equipamientos en los sistemas informáticos, multimedias y bibliográficos y la constitución de la red virtual de Institutos Superiores de Formación Docente en todo o país; e) la implementación de procesos de desarrollo profesional que atienden a directores y docentes en su formación continua y becas para postgraduación; f) la generación de espacios de acompañamiento de las trayectorias estudiantiles; g) la instalación de procesos de autoevaluación institucional en el marco del Programa de Mejora Institucional que recuperó el protagonismo de las instituciones; h) la difusión de las investigaciones nacionales e internacionales; apertura de la comunidad educativa del Centro de Documentación virtual do INFD (CEDOC); y i) el avance en la asistencia para el cumplimiento de los productos normativos que aseguren la cohesión del sistema, entre ellos el Régimen Académico Marco y los Reglamentos Orgánicos de cada jurisdicción (ARGENTINA, 2011).
\end{abstract}

Como explica Feldfeber (2010), la formación de profesores en la Argentina pasó por diversas transformaciones desde su inicio, en las Escuelas Normales. En función de las influencias de las orientaciones internacionales sigue siendo recurrente en las leyes y resoluciones, un énfasis dado a la relación entre formación docente y calidad de la educación, como propone la lógica neoliberal. Sin embargo, diferente de lo que acontece en Brasil, la autora muestra que, en la Argentina, se puede identificar dos tendencias referidas a la formación de profesores: una de continuidad con la lógica neoliberal y otra de ruptura con las políticas características de los años noventa, conforme se ha dicho. Para Feldfeber (2010), las metas del Plan Nacional de Formación Docente (2016-2021), e incluso el INFD, órgano creado por el Ministerio de educación, como "regulador responsable por planificar y ejecutar políticas de articulación del sistema de formación docente inicial y continua y por impulsar políticas de fortalecimiento de las relaciones entre el sistema de formación docente y otros niveles del sistema educativo", buscan superar los problemas de la formación de profesores argentinos (FELDFEBER, 2019, p. 1345).

A pesar de estos esfuerzos, según afirmaciones de Feldfeber (2019), las últimas décadas constituyeron un período de intensas contradicciones en el país. A partir de 2003, se observan algunos cambios en las políticas reformistas, por lo tanto, diferente de lo que ocurre actualmente en Brasil. En la gestión Kirchner (2003-2007) y de la Presidenta Cristina Kirchner (2007-2011/2011-2015), no sin dificultades, ocurrieron conflictos graves referentes al piso salarial de profesores, necesidad retomada de acuerdos con los sindicatos, garantía de mejora de las condiciones salariales que eran desiguales entre las jurisdicciones, mecanismos de compensación salarial, implementación de paritarias 
docentes, condiciones de trabajo, formación continua, participación y evaluación, financiamiento educativo. La sanción de la LEN que derogó la LFE, por ejemplo, constituye un hecho emblemático respecto al cuestionamiento de las políticas hegemónicas de los años noventa, aunque se mantengan algunos principios polémicos de esta última. En la LEN se incluyó la conceptualización de educación como bien público y como un derecho social y la responsabilidad del Estado como garante de ese derecho. En la LEN, "Ia formación docente tiene la finalidad de preparar profesionales capaces de enseñar, generar y transmitir los conocimientos y valores necesarios para la formación integral de las personas, el desarrollo nacional y la construcción de una sociedad más justa" (FELDFEBER, 2019, p. 134).

El juego de intereses cambia la escena con el mandato de Macri (2015-2018), cuando se produjo una vuelta a la agenda hegemónica en la Argentina. En un contexto de "restauración conservadora" de clara filiación a principios neoliberales y neoconservadores, la política de modernización del Estado del macrismo se desarrolló desde el paradigma del gerencialismo denominado Nueva Gestión Pública (NGP) (Ball y Youdell, 2008: 25-27). Este paradigma se caracteriza por sus tendencias privatizadoras, sustentado en teorías económicas procedentes del management público (Guerrero, 2004) y a otras no económicas: neurociencias aplicadas a la educación con su derivación darwinista y un espiritualismo new age como configuradores de las políticas. (Carli, 2017; Gioannini, 2019). Desde el punto de vista de las políticas educativas, a nivel nacional se aprobó el documento Plan Nacional de Formación Docente 2016-2021, en el que se establecen cuatro pilares básicos: justicia educativa, desarrollo de la profesión docente, centralidad en la práctica y renovación de la enseñanza. Tres son los objetivos que sustentan este plan: mejorar la calidad de la formación docente inicial, garantizar la cantidad necesaria de docentes con la titulación requerida y mejorar las prácticas de los equipos directivos y docentes en ejercicio. En este contexto se produce un achicamiento del presupuesto destinado a educación (cierre de áreas, programas y despidos en los cuadros técnicos de gobierno). La restauración conservadora pone a la educación ante una situación de dependencia de las jurisdicciones a las regulaciones nacionales, establecidas y consensuadas por los gobiernos y ministerios de educación provinciales. Pero, a la vez embisten de una cierta autonomía a las jurisdicciones en materia de programas y planes educativos, como también otorgan cierto poder de decisión sobre otros aspectos como la redefinición de ofertas de nivel superior con el cierre de carreras y aperturas de otras nuevas, en general de carácter técnico, como ocurrió en algunas jurisdicciones del país ${ }^{3}$. La propuesta política ultra-neoliberal del macrismo se acompañó con tendencias privatizadoras, tales como la tercerización de servicios de formación continua a fundaciones internacionales privadas ${ }^{4}$ y con una nueva "ola evaluadora" impulsando la autoevaluación institucional con la finalidad de promover procesos de mejora de la calidad educativa en este nivel educativo, evaluándose desempeños docentes y la dimensión institucional de los Institutos Superiores de Formación Docente del país. Todo indica que la formación docente frente a la fuerte influencia ultra neoliberal tiende a tornarse cautiva, como ocurre en Brasil (FELDFEBER, 2019). 
NOTA 5: ALGUNAS CONSIDERACIONES SOBRE LA FORMACIÓN DOCENTE EN TIEMPOS DE INFLUENCIA ULTRA NEOLIBERAL: BRASIL Y ARGENTINA

Actualmente, la formación de profesores brasileños y argentinos enfrenta los desafíos impuestos por el ascenso del ultra-neoliberalismo en América Latina. En ambos países, las políticas reformistas fueron justificadas en un diagnóstico anterior sobre educación, formación de profesores y funcionamiento de la mayoría de las universidades públicas, y aunque existan diferencias nacionales importantes que provienen de factores exógenos y endógenos de los propios países, nuestro análisis mostró cómo los profesores son vistos como "actores reformables que deben tener la voluntad de disposición de adquirir nuevos conocimientos, a lo largo de la vida, como explica Oliveira (2019, p.11). Idea asociada a las acciones que buscan remodelar las profesiones en el área de la educación, en Brasil y en Argentina, sobre una fuerte promoción de intervenciones regulatorias de los organismos internacionales.

En la particularidad del caso brasileño, con el ascenso conservador y fundamentalista del gobierno de Bolsonaro, la imposición de políticas de formación docente agudiza el individualismo, refuerzan las nociones de esfuerzo y mérito, intensificando la lógica de la competencia como principal directriz que rige las vidas de los profesores. El gobierno brasileño sigue imponiendo reformas educacionales directamente asociadas a los avances del ultra neoliberalismo.

Al contrario de Brasil, en diferentes momentos, la Argentina impulsó políticas públicas destinadas a dar respuestas a los graves problemas en términos de exclusión y desigualdad, provocados por el proceso de agudización neoliberal. Inclusive, algunas políticas, como aquellas presentes en el periodo de crisis de 2001, pasaron a generar procesos de ampliación de derechos e inclusión social que también tuvieron su expresión en el campo educativo" (FELDFEBER, 2019, p. 131). Sin embargo, existe una adhesión del gobierno argentino actual a las políticas de carácter neoliberal, como ocurre en Brasil, lo que responde a las directrices impuestas a la formación de profesores en América Latina. El gobierno de Alberto Fernández y Cristina Fernández de Kirchner que asumirá en el mes de diciembre de 2019 deberá enfrentar los requerimientos internos de las mayorías y el endeudamiento externo contraído en los últimos años del gobierno de Mauricio Macri, situación en la que la educación pública seguramente será parte del debate y de las luchas por parte de los actores educativos que a lo largo de la historia, contra los embates del neoliberalismo, han defendido la educación como un deber del Estado y un derecho de los ciudadanos.

Según Resende (2019), en la conferencia inaugural del curso de especialización de la Facultad de Educación / UFG/Brasil, hizo una analogía entre la universidad y la formación docente con el libro de García Marques "El amor en los tiempos del cólera", para ejemplificar aspectos que agudizan la formación docente. En el caso de Brasil, se fortalece una campaña de producción de odio: odio a los derechos de las minorías, a los pocos derechos adquiridos a lo largo de los años; odio al diferente, odio a la tolerancia, odio a la divergencia de pensamiento, odio a una supuesta crisis moral, responsable de la disolución de la "familia tradicional", un odio que es ideológicamente internalizado en las relaciones sociales como valores (IASI, 2016a). Inclusive autoriza (y también valora) el odio de clase, direccionado contra las organizaciones de izquierda, además de odio a la colectividad orientado contra los sindicatos y otras organizaciones de clase trabajadora, lo que trae serios problemas al colectivo de profesores. Resende sostiene que el modelo 
de ideología impuesto en América Latina favorece la Barbarie, como expresión de distopía.

Mientras tanto, las acciones ultra neoliberales no aceptan cualquier tipo de subversión o cambio en el orden impuesto, y, por consiguiente, aquellos que luchan por cambios sociales, como los profesores, uniéndose a los partidos de izquierda, sindicatos, movimientos sociales, asumiendo esos espacios como de discusión y resistencia, son duramente combatidos. Sin duda, la educación y la formación docente en ambos países, sufren las mismas imposiciones, tal vez porque pueden contribuir con una contrahegemonía y emprender la "lucha de los educadores" contra lo que ocurre en el tejido social (FREIRE, 1989).

Artigo recebido em: 09/12/2019 Aprovado para publicação em: 17/02/2020

\section{AGUDIZAÇÃO ULTRA NEOLIBERAL, EDUCAÇÃO E FORMAÇÃO DE PROFESSORES NO BRASIL E ARGENTINA}

RESUMO: O artigo analisa a evolução das políticas neoliberais no campo da educação em geral e na formação de professores, no Brasil e Argentina, desde os anos 90. Em primeiro lugar, assumimos que o neoliberalismo é considerado um movimento ideológico que, desde as décadas de 1970 e 1980, implusiona um período de reestruturação econômica, reajustes sociais e políticos, além de novas decisões governamentais de acordo com as diretrizes neoliberais mundiais. Destaca-se o papel de organizações internacionais como a UNESCO, o Banco Mundial e o BID como atores que tiveram um lugar fundamental na disseminação das ideias neoliberais, visando minimizar o papel do Estado e fortalecer a iniciativa privada, contribuindo diretamente para a manutenção da desigualdade. social. $\mathrm{O}$ texto abrange legislação, programas e projetos formulados e desenvolvidos no Brasil e na Argentina que, embora dêem conta de importantes diferenças nacionais derivadas de fatores exógenos e endógenos dos próprios países, expressando ao mesmo tempo o poder da influência reguladora de organizações internacionais na formação de professores.

PALAVRAS-CHAVE: Neoliberalismo. Políticas neoliberais. Formação de profesores.

ULTRA NEOLIBERAL DEVELOPMENT, TEACHER EDUCATION AND TRAINING IN BRAZIL AND ARGENTINA

ABSTRACT: The article analyzes the evolution of neoliberal policies in the field of education in general and teacher education in Brazil and Argentina since the 1990s. First, we assume that neoliberalism is considered an ideological movement that, since the 1970s and 1980, implied a period of economic restructuring, social and political readjustments, and new government decisions in accordance with world neoliberal guidelines. We highlight the role of international organizations such as UNESCO, the World Bank and the IDB as key players in the dissemination of neoliberal ideas, in order to minimize the role of the state and strengthen private initiative, 
MAGALHÃES, S. M. O.; ARAUJO, S.; ARGÜELLO, S. B.

contributing directly to the maintenance of inequality. . Social. The text covers legislation, programs and projects formulated and developed in Brazil and Argentina that, while accounting for important national differences derived from exogenous and endogenous factors of the countries themselves, while expressing the power of regulatory influence of international organizations in the formation of teachers.

KEYWORDS: Neoliberalism, Neoliberal Policies, Teacher Training.

\section{NOTAS}

1) “La Organización para la Cooperación y Desarrollo Económico - OCDE, con sede en París, Francia, es una organización internacional compuesta por 35 países miembros, que reúne las economías más avanzadas del mundo, junto a algunos países emergentes como Corea del Sur, Chile, o México y Turquía. La Organización fue fundada el 14 de diciembre de 1961, sucediendo a la Organización para la Cooperación Económica Europea, creada el 16 de abril de 1948" (BRASIL, 2019k).

2) Este proceso, único en el país, se continuó durante los años 2017 y 2019 con proyectos de evaluación externa autogestionados por las unidades académicas que siguieron el mismo modelo de investigación cualitativa, comprensiva y participativa, esta vez con el financiamiento de la Secretaría de Políticas Universitarias a través del Proyecto de Apoyo a la evaluación de los Profesorados Universitarios en Letras (Programa de Calidad Universitaria, SPU).

3) Como evidencia de esta "relativa autonomía", en el caso de la Jujuy, provincia del norte argentino, el gobierno actual, que sigue la línea política de "Cambiemos", partido que sostiene al Presidente Macri, sancionó el Decreto № 7320/17 "Plan Integral de Mejora del Sistema Formador Provincial", emitido por el Gobierno de dicha Provincia, dando inicio a un proceso de reordenamiento del sistema formador limitando la apertura de matrícula en algunas carreras y reasignando a los docentes del nivel otras funciones. Posteriormente, en 2019, se cerraron algunas carreras y se ofrecieron otras nuevas, cuya aprobación a nivel nacional, no se concretó a la fecha.

4) Como la International Varkey Foundation o la Fundación "Enseñá por argentina", entre otras. Este tipo de avance del comercio internacional en educación aplicado al caso argentino puede consultarse en Feldfeber et al, 2018.

5) Se hace referencia a una "nueva ola evaluadora", por cuanto como se dijo anteriormente en la década de los noventa, de la mano de la Ley Federal de Educación № 24.195 (1993) y de la Ley de Educación Superior № 24.521 (1995), se concretaron procesos de evaluación y acreditación institucional de los Institutos de Formación Docente junto a una reforma radical de las ofertas y funciones de dichas instituciones.

\section{REFERENCIAS}

ALLIAUD, A. La formación docente. Estado de situación y desafíos a futuro. Voces del Fénix. Voces del Fénix. Revista del Plan Fénix, Año 1, n.3, Sep./2010.

ALLIAUD, A. Estado de situación de la formación docente en Argentina. Políticas y Desafíos a futuro, 2009. Anais da XIII Conferencia Iberoamericana de Educación. Plan de Cooperación. Renovación de Ideas y Formulación de Estrategias tendientes al 
Agudización ultra neoliberal, educación y formación...

fortalecimiento de Políticas de Formación Docente. Tarija, Bolivia, 4 y 5 de septiembre de 2003.

ALLIAUD, A. Impacto de la historia del magisterio argentino y la formación docente. I Encuentro Virtual de Escuelas Normales: "Orígenes del Magisterio Argentino. Anais... Programas Archivos escolares y Memoria de la Educación Argentina (MEDAR), 2011.

ALLIAUD, A. Los maestros y su historia: los orígenes del magisterio argentino. Biblioteca Política Argentina. Buenos Aires: Centro Editor de América Latina, 1993. Estudios sobre la Educación, 434, 1993.

ANDERSON, P. Balanço do Neoliberalismo. In: SADER, Emir; GENTILI, Pablo (Orgs.). PósNeoliberalismo as políticas sociais e o Estado democrático. 5a Ed. Rio de Janeiro: Paz e Terra, 2000.

APPLE, M. W. O que os pós-modernistas esquecem: capital cultural e conhecimento oficial. In: GENTILI, P.; SILVA, T. T. da. (org.). Neoliberalismo, qualidade total e educação. Rio de Janeiro: Vozes, 2015.

ARGENTINA. Consejo Federal de Educación. Resolución n. 30/2007. (2007b) Disponível em: <http://www.me.gov.ar/consejo/resoluciones/res07/30-07.pdf >. Acesso em: 05/11/2019.

ARGENTINA. Consejo Federal de Educación. Resolución n. 563/2009, ANEXO. Proyectos de Integración, 2009.

ARGENTINA. Consejo Federal de Educación. Instituto Nacional de Formación Docente. Resolución n. 24/2007. Lineamientos Curriculares Nacionales para la Formación Docente Inicial. (2007a) Disponível em: <http://www.me.gov.ar/consejo/resoluciones/res07/2407-anexo01.pdf >. Acesso em: 05/06/2016.

ARGENTINA. Consejo Federal de Educación. Resolución n. 113/2008, ANEXO. Proyectos de Integración, 2008.

ARGENTINA. Consejo Federal de Educación. Resolución n. 140/2011. Lineamientos federales para el planeamiento y la organización institucional del sistema formador, 2011. FELDFEBER, Myriam. Una transformación sin consenso: apuntes sobre la política educativa de Menem, Versiones 11, Buenos Aires: Secretaría de Extensión Universitaria (UBA) y Ediciones Novedades Educativas. 2000.

ARGENTINA. Consejo Federal de Educación. Resolución n. 72/2008. O Sistema Nacional de Formación Docente, 2008. 
MAGALHÃES, S. M. O.; ARAUJO, S.; ARGÜELLO, S. B.

ARGENTINA. Las políticas de formación docente. In: Voces en el Fénix. Buenos Aires, n. 3, p. 26-29. Sep./2010. FELDFEBER, Myriam; GLUZ, Nora. Las políticas educativas en Argentina: herencias de los ' 90 , contradicciones y tendencias de "nuevo signo". Educação e Sociedade, Campinas, v. 32, n. 115, p. 339-356, abr./jun. 2011.

ARGENTINA. Ministerio de Educación. Ley de Educación Nacional n. 26.206/2006. Disponivel em: <http://www.me.gov.ar/doc_pdf/ley_de_educ_nac.pdf>. Acesso em: 05/11/2019.

ARGENTINA. Ministerio de Educación. Ley de Educación Superior, n. 24.541/1995. Disponível em: <http://www.coneau.edu.ar/archivos/447.pdf>. Acesso em: 05/11/2019.

ARGENTINA. Ministerio de Educación Ciencia y Tecnología, Consejo Federal de Educación (2016). Resolución CFE No 286/16 Plan Nacional de Formación Docente 20162021. Disponible en: http://www.bnm.me.gov.ar/giga1/documentos/EL005991.pdf Acesso em: 05/11/2019.

ARGENTINA. Ministerio de Educación Ciencia y Tecnología, Consejo Federal de Educación (2018). Resolución № 33/18: Documento “Marco Referencial de Capacidades Profesionales de la Formación Docente Inicial". Disponible en:

http://www.bnm.me.gov.ar/giga1/normas/RCFE_337-18.pdf Acesso em: 05/11/2019.

ARGENTINA. Gobierno de la Provincia de Jujuy, Poder Ejecutivo (2017). Decreto № 7320/17 "Plan Integral de Mejora del Sistema Formador Provincial". Acesso em: 05/11/2019.

ARGENTINA, Ministerio de Educación, Ciencia y Tecnología, Presidencia de la Nación, Secretaría de Evaluación Educativa, Argentina (2018): Documento Marco "Autoevaluación de institutos de formación docente". Agosto de 2018. Disponible en: https://www.argentina.gob.ar/educacion/evaluacion-educativa/autoevaluacion-ifd Acesso em: 05/11/2019.

ASSOCIAÇÃO NACIONAL DE PÓS-GRADUAÇÃO E PESQUISA EM EDUCAÇÃO. ANPED. Nota sobre a audiência pública da BNCC em Belém. ANPED. Rio de Janeiro, RJ: Associação Nacional de Pós-Graduação e Pesquisa em Educação, 2018. Disponível em: <http://www.anped.org.br/news/nota-sobre-audiencia-publica-da-bncc-em-belem>. Acesso em: 20 jun. 2019a.

ASSOCIAÇÃO NACIONAL DE PÓS-GRADUAÇÃO E PESQUISA EM EDUCAÇÃO. ANPED. Base Nacional Comum Curricular (BNCC) foi tema de debate entre associações científicas em colóquio promovido pela ANPEd; novo documento será entregue ao CNE esta semana pelo MEC. ANPED. Rio de Janeiro, RJ: Associação Nacional de Pós-Graduação e Pesquisa em Educação, 2016. Disponível em: <http://www.anped.org.br/news/basenacional-comum-curricular-bncc-foi-tema-de-debate-entre-associacoes-cientificas-em>. Acesso em: 12 jul. 2019b. 


\begin{abstract}
ASSOCIAÇÃO NACIONAL DE PÓS-GRADUAÇÃO E PESQUISA EM EDUCAÇÃO. ANPED. Uma formação formatada. 2019 Disponível em:http://www.anped.org.br/sites/default/files/images/posicao_da_anped_sobre_o_te xto_referencia_diretrizes_curriculares_nacionais_e_base_nacional_comum_para_a_for macao_inicial_e_continuada_de_professores_da_educ.pdf Acesso em: 19/10/2019c.

BALL, S.; YOUDELL, D., La privatización encubierta en la educación pública. Instituto de Educación, Universidad de Londres. Internacional de la Educación. 2008. Disponible em: http://firgoa.usc.es/drupal/files/2007-00242-01-S.pdf Acesso em: 05/11/2019.
\end{abstract}

BEECH, Jason. A internacionalização das políticas educativas na América Latina.

Currículo sem Fronteiras, v.9, n.2, pp.32-50, Jul/Dez 2009.

BRASIL. Base Nacional Comum Curricular. Brasília: Ministério da Educação, 2017. Disponível em: http://basenacionalcomum.mec.gov.br/. Acesso em: 10 jan. 2018.

BRASIL. Congresso Nacional. Lei 13.005 de 25 de junho de 2014. Plano Nacional de Educação 2014-2024. Brasília, 2014.

BRASIL. Constituição (1988). Constituição da República Federativa do Brasil. Brasília: Senado Federal, 1988.

BRASIL. Emenda Constitucional n 85, de 26 de fevereiro de 2015. Altera e adiciona dispositivos na Constituição Federal para atualizar o tratamento das atividades de ciência, tecnologia e inovação. Disponível em <http://www.

planalto.gov.br/ccivil_03/constituicao/emendas/emc/emc85.htm> Acesso em 28 dez. 2018.

BRASIL. Lei no 13.005, de 25 de junho de 2014. Plano Nacional de Educação (PNE 2014 2024). Brasília, DF, 2014.

BRASIL. Ministério da Educação. CNE/CP. Parecer n. 02/2015, aprovado em 9 de junho de 2015. Diretrizes Curriculares Nacionais para a Formação Inicial e Continuada dos Profissionais do Magistério da Educação Básica. Brasília, 2015a.

BRASIL. Ministério da Educação. Conselho Nacional de Educação. Resolução CNE/CP n. 2 de 1 julho de 2015. Diretrizes Curriculares Nacionais para a formação inicial em nível superior (cursos de licenciatura, cursos de formação pedagógica para graduados e cursos de segunda licenciatura) e para a formação continuada. Brasília, 2015b.

BRASIL. Ministério da Educação. Diretrizes Curriculares Nacionais Gerais da Educação Básica. Secretaria de Educação Básica. Diretoria de Currículos e Educação Integral. Brasília: MEC, SEB, DICEI, 2013, p. 374-415, 2013a. Disponível em: 
$<$ http://portal.mec.gov.br/docman/julho-2013-pdf/13677-diretrizes-educacao-basica2013-pdf/file>. Acesso em: 20 dez. 2018.

BRASIL. Ministério da Educação. Lei de Diretrizes e Bases da Educação Nacional. Lei no 9394. De 20 de dezembro de 1996. Estabelece as diretrizes e bases da educação nacional. Brasília, DF, 1996.

BRASIL. Ministério da Educação. Proposta para Base Nacional Comum da Formação de Professores da Educação Básica (Versão Preliminar). Brasília, DF: Ministério da Educação, 2018f. Disponível em:

$<$ http://portal.mec.gov.br/index.php?option=com_docman\&view=download\&alias=105 091-bnc-formacao-de-professores-v0\&category_slug=dezembro-2018pdf\&ltemid=30192>. Acesso em: 20 fev. 2019.

BRASIL. Projeto de Lei do Senado $n^{\circ} 193$ de 2016. Diretrizes e bases da educação nacional, de que trata a Lei no 9.394, de 20 de dezembro de 1996, o "Programa Escola sem Partido". 2016h. Disponível em:

<https://www12.senado.leg.br/ecidadania/visualizacaomateria?id=125666>. Acesso: 27 jun. 2018.

BRASIL. Resolução CNE/CP n 2/2015. Diretrizes Curriculares Nacionais para a Formação Inicial e Continuada em Nível Superior de Profissionais do Magistério para a Educação Básica (DCN's, 2015). Acesso em: 05/11/2019.

BRZEZINSKI, I. Política de formação de professores: a formação do professor "primário" na Lei no 9.394/96 e em seus desdobramentos. In: BRZEZINSKI, Iria (org.). LDB interpretada: diversos olhares se entrecruzam. 10.ed. São Paulo: Cortez, 2007. p. 169196.

BRZEZINSKI, Iria. Formação de Professores: A Dimensão Política e o Compromisso Social do Pedagogo como Professor, Investigador e Gestor Educacional. Revista Brasileira de Formação de Professores, vol. 1, n. 3, p.51-75, dezembro, 2009.

CARLI, S. "Management público, conservadurismo y reocupación estatal: el lugar de las universidades públicas". En Filmus, D., Educar para el mercado. Escuela, universidad y ciencia en tiempo de neoliberalismo. (pp. 101-129). Bs.As.: Octubre Editorial, 2017.

CARNOY, M. Globalización y reestructuración de la educación. Revista de Educación, $n$. 318, pp. 145-162.

CASTRO, M. R. A crise do capital e a luta de classes na educação: uma análise preliminar do ataque conservador ao colégio Pedro Il pelo escola sem partido. Rev. HISTEDBR Online. Campinas, v.19, 2019. 
CHECA, L.; ARGÜELLO, S. (Coords.). "Génesis de la autoevaluación participativa de la carrera de profesorado en letras de la Facultad de Humanidades y Ciencias Sociales de la Universidad Nacional de Jujuy". En: Macchiarola, V. y Perassi, Z.: Investigar para evaluar y transformar. Experiencias de investigación evaluativa de profesorados universitarios en Letras. Río Cuarto, Argentina: UniRío Editora, 2018. (pp. 229-316)

COSMO, C. de C; FERNANDES, S. A. de S. Neoliberalismo e educação - lógicas e contradições. VIII Seminário Nacional de Estudos e Pesquisas “História, Sociedade e Educação no Brasil". São Paulo, Unicamp, 2009.

CURY, C. R. J.; REIS, M.; ZANARDI, T. A. C. Base Nacional Comum Curricular: dilemas e perspectivas. São Paulo: Cortez, 2018.

FELDFEBER, M.; GLUZ, N. Las políticas educativas en Argentina: herencias de los '90, contradicciones y tendencias de "nuevo signo". Educação e Sociedade, Campinas, v. 32, n. 115, p. 339-356, abr./jun. 2011.

FELDFEBER, M.. Las políticas de formación docente. In: Voces en el Fénix. Buenos Aires, n. 3, p. 26-29. Sep./2010.

FELDFEBER, M.; PUIGRÓS, A.; ROBERSTON, S.; DUHALADE, M.. La privatización en Argentina. Buenos Aires: CTERA, 2018. Disponible en: https://ei-ieal.org/sites/default/files/docs/investigacion_argentina_0.pdf Acesso em: 05/11/2019.

FREIRE, P. Pedagogia do oprimido. 9a ed. São Paulo: Paz e Terra, 1987.

FREITAS, L. C. de. BNCC da Formação: entidades se manifestam. Avaliação Educacional, Blog do Freitas, 2018. Disponível em:

$<$ https://avaliacaoeducacional.com/2018/12/19/bnc-da-formacao-entidades-semanifestam/>. Acesso em: 20 abr. 2019 a.

FREITAS, L. C. de. Os reformadores empresariais da educação: da desmoralização do magistério à destruição do sistema público de educação. Educ. Soc., Campinas, v. 33, n. 119, p. 379-404, Junho de 2012. Disponível em:

$<$ http://www.scielo.br/scielo.php?script=sci_arttext\&pid=S0101733020120

00200004\&lng=en\&nrm=iso $>$ Acesso em $10 \mathrm{fev} .2019 \mathrm{~b}$.

FRIGOTTO, G. Educação e formação humana: ajuste neoconservador e alternativa democrática. In: GENTILI, P. A. A.; SILVA, T. T. da. (org.). Neoliberalismo, qualidade total e educação. Rio de Janeiro: Vozes, 2015. p. 31-92. 
MAGALHÃES, S. M. O.; ARAUJO, S.; ARGÜELLO, S. B.

GENTILI, P. A. A. Neoliberalismo e educação: manual do usuário. In: SILVA, T. T. da.; GENTILI, P. A. A. (org.). Escola S. A.: quem ganha e quem perda no mercado educacional do neoliberalismo. Brasília: CNTE, 1996. p. 9-49

GENTILI, P. A falsificação do consenso: simulacro e imposição na reforma educacional do neoliberalismo. Petrópolis: Vozes, 1998.

GIOANINI, M. S.; SRI SRI, M. Consejos presidenciales para una vida exitosa. Análisis de la nueva era en el discurso oficial del presidente Mauricio Macri". Hologramática. Facultad de Ciencias Sociales, UNLZ. Año XV, № 29, V1 (2019), pp. 57-79.

GOMES, F. A. Base Nacional Comum Curricular do Ensino Médio: Currículo poder e resistência. Tese de doutorado. PUC -GO, 2019.

GOMES, F. A. Políticas emergenciais de formação continuada de professores da educação básica: estudo da REDE (2009) e do PARFOR (2009) no governo popular brasileiro. Dissertação (Mestrado Interdisciplinar em Educação, Linguagem e Tecnologias), Universidade Estadual de Goiás - UEG, Goiás, 2014.

GUERRERO, O. (2004). "El mito del nuevo management público". Revista Venezolana de Gerencia. Vol. 9, № 25, enero-marzo 2004, PPL-54.

HARVEY, D. Neoliberalism: A brief history. Oxford University press, 2005.

HARVEY, D. O neoliberalismo: história e implicações. São Paulo: Edições Loyola, 2009.

IASI, M. L. O “petismo" como problema moral. Disponível em: https://blogdaboitempo.com.br/2016/09/07/o-petismo-como-problema-moral/. Acesso em: 29 set. 2016a. Sem paginação.

IASI, M. L. Reflexão sobre o processo de consciência. Ensaios sobre consciência e emancipação. 2. ed. São Paulo: Expressão Popular, 2011. p. 11-45. Sem paginação.

IASI, M. L. Três crises... falta uma. Disponível em: https://blogdaboitempo.com.br/2015/08/12/tres-crises-falta-uma/. Acesso em: 29 set. 2016b. Sem paginação.

KROTSCH, P. El proceso de formación e implementación de las políticas de evaluación de la calidad en la Argentina, en Pedro Krotsch (organizador). La universidad cautiva. Legados, marcas y horizontes. La Plata: Al Margen, Facultad de Humanidades y Ciencias de la Educación, UNLP, 2002.

LAGOA, M. I. A ofensiva neoliberal e o pensamento reacionário-conservador na política educacional brasileira. Rev. HISTEDBR On-line. v.19, p. 1-14. Campinas, SP, 2019. 
Agudización ultra neoliberal, educación y formación...

Dossiê 78

LIBÂNEO, J. C., OLIVEIRA, J.F., THOSCHI, M.S. Educação escolar: políticas, estrutura e organização. São Paulo, SP: Cortez, 2003.

LLIAUD, A. La formación docente en Argentina. Aproximación a un análisis político de la situación. Itinerarios educativos, v. 6, p. 197-214, 2012-2013.

MARINO, G.. Formação docente na Argentina: políticas e sistema formador. VII Seminário Educação e Formação Humana: desafios do tempo presente. I Simpósio Educação, Formação e Trabalho. Belo Horizonte: Nova Gameleira. Centro Federal de Educação Tecnológica de Minas Gerais (CEFET-MG), 2019.

MISURACA, M. R.; MENGHINI, R. A. La formación de docentes en la Argentina del siglo XXI: ¿consolidación de las tendencias de los 90?. Profesorado: Revista de Currículum y Formación de Profesorado, v. 14, n. 2, 2010, pp. 251-266. Granada, Universidad de Granada.

MOURA, E. da S.; NAJJAR, J.; CARNEIRO, W. Neoliberalização e reforma educacional: a chegada da organização Teach for America no Brasil. RBPAE- v. 35, n. 2, p. 447 - 468 , mai./ago. 2019.

NEVES, L. Brasil século XXI: propostas educacionais em disputa. In: LOMBARDI, José; SANFELICE, J. (Org.). Liberalismo e educação em debate. Campinas/SP: Autores Associados, 2007. p. 205-224.

NEVES, L. M. W. O professor como intelectual estratégico na disseminação da nova pedagogia da hegemonia. Trabalho encomendado para apresentado na 36a Reunião Anual da Associação Nacional de Pós-Graduação e Pesquisa em Educação (ANPEd), Goiânia-Go, 29/09 a 02/10 de 2013.

OLIVEIRA, D. A.; FELDFEBER, M. (Comp.) Nuevas regulaciones educativas en América Latina: políticas y procesos del trabajo docente. Lima: Fondo Editorial Universidad de Ciencias y Humanidades, 2010.

ORSO, P. J. Neoliberalismo: equívocos e consequências. In: LOMBARDI, J. C.; SANFELICE, J. L. (Orgs.). Liberalismo e educação em debate. Campinas: Autores e Associados, Histedbr, 2007, p. 163183.

PUIGGRÓS, A. Las alternativas cambian con el tiempo. In: PUIGGRÓS, A. De Simón Rodríguez à Paulo Freire: educación para la integración ibero-americana. Buenos Aires: Colihue, 2010, p. 7-37.

RESENDE, A. Aula inaugural do curso de Especialização em Psicologia dos Processos Educativos. Anotações. Faculdade de Educação. Universidade Federal de Goiás, 2019. 
ROJAS, M. L. Educación superior en Argentina: ¿um sistema fuera de control? Revista de la Educación Superior, v. XLI (I), n. 161, pp. 93-114, ene./mar.2012.

SANGENIS, L.F.C, OLIVEIRA, E.F.R., and CARREIRO, H.J.S., eds. Formação de professores para uma educação plural e democrática: narrativas, saberes, práticas e políticas educativas na América Latina [online]. Rio de Janeiro: EdUERJ, 2018. Pesquisa em educação / Formação de profesores, 2018.

SAVIANI, D. História das Idéias Pedagógicas no Brasil. Campinas: Autores e Associados, 2007.

SCHEIBE, L. Formação de professores no Brasil: a herança histórica. Revista Retratos da Escola, Brasília, v. 2, n. 2-3, p. 41-53, jan./dez. 2008.

SHIROMA, E. O.; MORAES, M. C. M. de; EVANGELISTA, O. Política educacional. Rio de Janeiro, Lamparina, 2011.

SILVA, M. R. da.; MOURA ABREU, C. B. de. Reformas para quê? As políticas educacionais nos anos de 1990, o "novo projeto de formação" e os resultados das avaliações nacionais. Perspectiva, v. 26, n. 2, p. 523-550, 2008.

SHUGURENSKY, D. La reestructuración de la educación superior en la era de la globalización: ¿hacia un modelo heterónomo?, en Alcántara Santuario, Armando; Pozas Horcasitas, Ricardo y Torres, Carlos Alberto (coords.). Educación, democracia y desarrollo en el fin de siglo. México: Siglo XXI, 1998.

FANELLI, A.; M. G. de. La Reforma de la Educación Superior en la Argentina: entre el Mercado, la Regulación Estatal y la Lógica de las Instituciones. NUPES Núcleo de Pesquisas sobre Ensino Superior.Universidade de São Paulo, 1997.

Solange Martins Oliveira Magalhães: Doctora en Educación. Profesora asociada de la Universidad Federal de Goiás, se desempeña en el curso de Pedagogía y Post-Graduación en Educación de la FE/UFG. Desarrolla investigaciones sobre la formación de profesores(as), y vinculada a la Línea de Investigación Formación, profesionalización y trabajo docente. Es coordinadora de la Redecentro en Goiás. Miembro del Observatorio Internacional de la Profesión Docente - OBIPD y de la Red de Dirección Estratégica en la Educación Superior (RED-DEES).

Orcid: https://orcid.org/0000-0003-1187-112X

E-mail: solufg@hotmail.com 
Sonia Araujo: Doctora en Filosofía y Ciencias de la Educación (UNED). Magíster y Diploma Superior en Ciencias Sociales con mención en Educación (FLACSO). Investigadora del Núcleo de Estudios Educacionales y Sociales (NEES) de la Facultad de Ciencias Humanas de la UNCPBA. Directora del proyecto de investigación Los procesos de formación y evaluación en la Universidad: Políticas, disciplinas, actores y prácticas. Coordinadora por la UNCPBA de la Red: Dilemas de nuevas culturas de producción de conocimiento. Los postgrados en Argentina, Brasil y Paraguay en el contexto de la evaluación de la calidad de la Educación Superior. Investigadora Categoría I. Docente de posgrado, directora y evaluadora de tesis en carreras de especialización, maestría y doctorado. Evaluadora de proyectos de investigación, investigadores y becarios, y de artículos científicos en el área de la educación.

Orcid: https://orcid.org/0000-0002-7692-1821

E-mail:saraujo@fch.unicen.edu.ar

Susana Beatriz Argüello: Mgter en Políticas Sociales (U.N.Sa.) y Doctoranda en Ciencias Sociales (UNJu). Profesora Titular en la carrera de Profesorado y Licenciatura en Ciencias de la Educación de la Universidad Nacional de Jujuy. Directora de la Especialización en Investigación Educativa de la misma universidad. Investigadora (Categoría II) sobre temáticas vinculadas a la formación docente y la educación superior. Directora del Proyecto "La formación permanente de profesores en la Provincia de Jujuy. Sujetos, políticas, instituciones y experiencias" (SECTER-UNJu). Se desempeña como docente de posgrado en distintas carreras de la UNJu, directora y evaluadora de tesis en carreras de grado y posgrado. Evaluadora de proyectos, investigadores y becarios de investigación y referatista de revistas científicas.

Orcid: https://orcid.org/0000-0003-2356-2391

E-mail: sbargüellojujuy@smail.com

Este periódico utiliza a licença Creative Commons Attribution 3.0, para periódicos de acesso aberto (Open Archives Iniciative - OAI). 